\title{
A CULTURA DA IMAGEM E UMA NOVA PRODUÇÃO SUBJETIVA $^{1}$
}

\author{
Luciana Lobo Miranda*
}

\section{ResUmo}

O presente trabalho discute a Cultura da Imagem como um modo de subjetivação na contemporaneidade. Pretende-se investigar quais as implicaçôes da reprodutibilidade técnica/tecnológica das imagens no âmbito da subjetividade. O conceito de aura de Walter Benjamin é aqui redimensionado como balizador dessa discussão. Foi no surgimento das imagens tecnologicamente reproduzidas que ocorreu a perda da aura das artes. A cultura da imagem, no entanto, capturou esta aura, instrumentalizando-a. Quais seriam as conseqüências para a subjetividade? Sujeição absoluta à tirania da imagem? Ou que outros mecanismos ela é capaz de engendrar, utilizando os mesmos aparatos tecnológicos, no combate à submissão?

Palavras-chave: subjetividade, imagem-técnica, aura

\section{Abstract}

\section{IMAGE CULTURE AND A NEW PRODUCTION OF SUBJECTIVITY}

The present work discusses the image culture as a way of producing subjectivity in contemporary world. We intend to investigate the implications of technical and technological reproductibility of images in the spectrum of subjectivity. The concept of aura as described by Walter Benjamin is here redimensioned in face of the current discussion. When technologically reproduced images appeared, the aura in arts was lost. The image culture, however, captured this aura, turning it into an instrument. What would be the consequences of this process for subjectivity? Have we become slaves to the tyranny of images? Or what other mechanisms is it capable to produce using the same technological apparatus facing submission?

Keywords: subjectivity, image technique, aura

\footnotetext{
* Doutora em Psicologia pela Pontifícia Universidade Católica do Rio de Janeiro; Professora do Programa de Pós-Graduação em Psicologia da Universidade Federal do Ceará.
} 
Hoje somos bombardeados por uma tal quantidade de imagens a ponto de não podermos distinguir mais a experiência direta daquilo que vimos há poucos segundos na televisão. Em nossa memória se depositam, por traços sucessivos, mil estilhaços de imagens, semelhantes a um depósito de lixo, onde é cada vez menos provável que uma delas adquira relevo. Ítalo Calvino (1990: 107)

Nossa análise inicia-se apresentando uma situação paradoxal: na "civilização da imagem”, o homem estaria perdendo a capacidade de imaginar e contar histórias dignas de serem narradas. A quantidade de imagens pré-fabricadas engendraria, segundo Calvino (1990), falta de imaginação. A emergência das tecnologias da imagem ainda na segunda metade do século XIX, com a invenção da fotografia e do cinema e, mais recentemente, o vídeo e o computador, vem influenciando decisivamente o modo como a leitura do mundo acontece na sociedade contemporânea. Segundo Fulchignoni (citado por Aumont, 1995), a "civilização da imagem" revela a situação de um mundo onde a quantidade, as modalidades e o intercâmbio de imagens são a cada dia mais numerosos.

Questôes como a massificação da cultura e a reprodutibilidade da arte atravessam não apenas a esfera macro político-sócio-econômica, mas a subjetividade contemporânea ${ }^{2}$. Assim, a "cultura da imagem", termo mais próximo de nossa análise, administra não apenas o espaço social, mas, sobretudo, o espaço subjetivo, haja vista a indissociabilidade entre o social e o psíquico. Ela é capilar, atuando no plano sensível, incidindo na forma como o sujeito se posiciona no mundo e se relaciona com ele mesmo.

Por outro lado, as imagens sempre funcionaram como mediação efetiva da relação do homem com o mundo: nos desenhos nas cavernas, nos totens, nas esculturas, nas pinturas... Por que buscarmos, então, a especificidade de nossa época na caracterização do que chamaremos cultura da imagem? E qual a especificidade de nossa época?

\section{A SUBJETIVIDADE NA ÉPOCA DA IMAGEM TÉCNICA ${ }^{3}$}

Comecemos, então, pela afirmação de Debray (1992):

Nós não acreditamos mais verdadeiramente que a estátua de Santa Geneviève protege Paris e que a Majestade de Conques cura a lepra e as hemorróidas. Nós não cobrimos mais os espelhos quando há um morto na casa, com medo de partir com ele [...], e colocar espinhos nas fotos de meu inimigo não é mais uma maneira útil de matar o tempo (Debray, 1992: 16-17; tradução nossa). 
Mesmo levando em consideração que tal afirmação pode ser relativizada, pois, conforme a religião e o culto, há ainda, no ocidente, relações sacralizadas com a imagem, presentes em peregrinações, lugares sagrados ou em imagens utilizadas para a proteção de lares e pessoas, é certo que, neste mesmo ocidente, vivese um estado laico, o que faz uma diferença na relação que mantemos com estas imagens sacralizadas e com o mundo de uma maneira mais ampla.

O fato de as imagens terem passado para o domínio comum não as fez perder o seu mistério... Debray (1992) fala a respeito do olhar crédulo que nosso tempo, dito incrédulo, pousa sobre as telas. Porém, se o mistério se mantém, ele é de outra ordem. As imagens caíram no domínio comum, fazendo com que mantenhamos outro tipo de relação com elas. Tal fator deve-se a constatações de que as imagens também mudaram o seu próprio estatuto. A possibilidade de sua reprodução infinita coloca-se, ao nosso ver, como o eixo central para esta transformação do que estamos nomeando cultura da imagem. Se antes as imagens produzidas pelo homem eram produtos artesanais e/ou artísticos, como as pinturas ou esculturas, ou passíveis de serem reproduzidas como a gravura e a litografia, há uma diferença intrínseca àquelas que começam a se desenvolver, a partir da primeira metade do século XIX, com o daguerreótipo, que, em 1839, inaugura uma fase de transição rumo às indústrias visuais ${ }^{4}$.

Apesar de a obra de arte sempre ter sido passível de reprodução, através de cópias ou imitações, sejam de discípulos ou de falsários, as técnicas de reprodução constituem um fenômeno relativamente novo, que passa necessariamente pela invenção da litografia e da imprensa, culminando com a invenção da fotografia e do cinema. Vejamos o que diz Benjamim (1936/1975)

Com a litografia, as técnicas de reprodução marcaram um progresso decisivo [...]. Assim, doravante, pôde o desenho ilustrar a atualidade cotidiana. E nisso ele se tornou íntimo colaborador da imprensa. Porém, decorridas apenas algumas dezenas de anos após essa descoberta, a fotografia viria a suplantálo em tal papel. Com ela, pela primeira vez, no tocante à reprodução de imagens, a mão encontrou-se demitida das tarefas artísticas essenciais que, daí em diante, foram reservadas ao olho fixo da objetiva. Como, todavia, o olho capta mais rapidamente do que a mão ao desenhar, a reprodução das imagens, a partir de então, pôde se concretizar num ritmo tão acelerado que chegou a seguir a própria cadência das palavras. [...] A litografia abria perspectivas para o jornal ilustrado; a fotografia já continha o germe do cinema falado (Benjamin, [1936] 1975: 12). 
A reprodução em larga escala representa não só uma mudança de suporte, mas altera a relação do sujeito com as obras de arte e, no limite, com as imagens em geral, pois uma estátua impressa num papel não será mais a mesma estátua. Porém uma fotografia reproduzida infinitamente continua sendo ela mesma. Segundo Debray (1992), passamos de uma técnica relacionada à imagem, seja na gravura, ou na litografia, para uma tecnologia da imagem, onde o processo é bem mais impessoal.

Machado (1994) discute o conceito de imagem técnica como mediação de apreensão da realidade. Para o autor, seu ideal é estar imune à "subjetividade" humana. Porém o próprio conceito de imagem técnica já é problemático, pois qualquer imagem, salvo as interiores, supõe dispositivos técnicos (ex. pintura, gravura, serigrafia). Vejamos, então, uma de suas conceituações para tentar delimitar o seu campo de análise:

Por "imagens técnicas" designamos em geral uma classe de fenômenos audiovisuais em que o adjetivo ("técnico") de alguma forma ofusca o substantivo (“imagem”), em que o papel da máquina (ou seja lá qual for a mediação técnica) se torna tão determinante a ponto de muitas vezes eclipsar ou mesmo substituir o trabalho de concepção de imagens por parte do sujeito criador, o artista que traduz as suas imagens interiores em obras dotadas de significado numa sociedade de homens (Machado, 1994: 10).

Aprofundando um pouco mais a questão: as próprias imagens mentais, a princípio puramente subjetivas, não se formam de imediato, mas a partir de traços mnemônicos. Pois bem, segundo Virilio (1994), desde a invenção do telescópio, com o distante tornando-se cada vez mais próximo, inaugurou-se um tipo de percepção onde a retenção torna-se cada vez problemática. A multiplicação de instrumentos técnicos óticos ou, como preferiu chamar Virilio, as máquinas de visão, que se apresentam como mediadores da relação do homem com o mundo, e os avanços tecnológicos dos transportes alteram o campo perceptivo do sujeito contemporâneo.

Com a multiplicação industrial das próteses visuais e audiovisuais, a utilização não-moderada destes materiais de transmissão instantânea desde a mais tenra idade, assiste-se a partir de então a uma codificação das imagens mentais cada vez mais elaborada, com a redução do tempo de retenção e sem grande recuperação ulterior, uma rápida derrocada da consolidação mnésica (Virilio, 1994: 21-22) 
Atualmente, a fala, o gesto não acompanham mais a hipervelocidade dos estímulos visuais, provocando não um salto qualitativo em relação às imagens, mas uma espécie de dislexia visual. A consciência passa a ser substituída por máquinas de visão que aceleram o tempo, no mesmo momento em que contraem o espaço. Virilio (1994) se baseia em estudos perceptivos contemporâneos para afirmar, em outras palavras, que a intensa aceleração do ritmo das imagens alteraria a profundidade de campo, empobrecendo a visão e, em última instância, alterando o princípio de realidade. Assim, a relação espaço-temporal, numa velocidade cada vez maior, faria com que as imagens mentais estivessem irremediavelmente atravessadas por estas tecnologias da imagem. Parafraseando o pintor Paul Klee, que diz "agora os objetos me percebem" (citado por Virilio, 1994: 86), o autor assim reflete: a um só tempo nos tornamos cada vez mais dependentes destas máquinas de visão para percebermos o mundo e a nós mesmos e assistimos à falência da imaginação, a uma industrialização da visão, em última instância, à não-visão.

Será que estamos, então, definitivamente aprisionados nos estilhaços de imagens, de que nos fala Calvino (1990), desfigurando nossas relações com o conhecimento, com os nossos desejos e com os outros, numa instrumentalização não só da visão, mas da própria existência? Até que ponto a subjetividade, na cultura da imagem, se deixa submergir na profusão intermitente de estímulos visuais, colocando-se apassivada e sem rumo? Ou que outros mecanismos ela é capaz de colocar em jogo com o intuito de se preservar e reagir de modo criativo, através do uso destes mesmos aparatos tecnológicos, superando o constrangimento do bombardeio sensorial?

Voltando à definição trazida por Machado (1994), ela nos ajuda a entender o ideal de objetividade e de representação da realidade trazida desde os primórdios da imagem técnica e que, ainda hoje, de certa forma, se mantém, na "imagem tecnológica”. Segundo o autor, o marco da imagem técnica foi o Renascimento italiano, onde artistas negaram suas imagens interiores e criaram dispositivos técnicos, aliados ao conhecimento científico da época, a fim de garantir a objetividade da coisa representada, visando a um total controle do visível. A fotografia e o cinema, segundo o autor, são filhas legítimas deste paradigma. E, se hoje a representação do real não lhes é hegemônica, é sem dúvida ainda predominante. Ao nosso ver, o vídeo e a televisão representariam o prolongamento deste mesmo paradigma ${ }^{6}$.

As máquinas de visão possibilitam o aclaramento dos detalhes imperceptíveis aos olhos humanos. O olhar humano é subtraído da busca da objetividade, que passa a ser delegada aos instrumentos óticos. Fotos, vídeos são cada vez mais utilizados como prova de veracidade (assim como o gravador e outros dispositivos 
técnicos sonoros), para fins policiais, militares, científicos ou jornalísticos, bem como para a razão do Estado. A verdade está na imagem captada pelas máquinas de visão e reproduzida infinitamente.

O cinema, em seu primórdio, também passou por um uso científico. Antes de ser considerado como "a fábrica dos sonhos", o cinema atendeu à necessidade dos cientistas de estudarem o movimento, a ponto de o próprio Lumière, logo após a primeira exibição da famosa cena do trem entrando na estação e assustando a platéia que sai correndo atemorizada e deslumbrada, desaconselhar Meliès a adquirir um cinematógrapho, pois, mesmo que o público se divertisse com ele, a novidade logo cansaria (Bernardet, 1980). Não há dúvidas sobre o engano de Lumière. A despeito de o público não mais fugir das projeções, modificando consideravelmente a relação da imagem com o espectador, cada vez mais familiarizado com sua linguagem e suas transformações, a ilusão de verdade ainda se mantém em boa parte do cinema.

Essa ilusão de verdade, que se chama impressão de realidade, foi provavelmente a base do grande sucesso do cinema. O cinema dá a impressão de que é a própria vida que vemos na tela, brigas verdadeiras, amores verdadeiros. Mesmo quando se trata de algo que sabemos não ser verdadeiro [...]. No cinema, fantasia ou não, a realidade se impõe com toda força (Bernardet, 1980: 13).

A idéia de veracidade ganha ainda mais força no documentário e na sua radicalidade, o chamado cinéma-verité. Carrière (1995) questiona a pretensão de alguns diretores de fazer cinema no qual a objetividade e a neutralidade sejam o fim último, pois seja no documentário, seja no cinema-verité, há sempre uma interpretação do real, isto é, há sempre um trabalho autoral, subjetivo. "Mas o que dizer do enquadramento, que circunscreve um determinado trecho da rua? $\mathrm{Ou}$ das lentes imóveis ante o tempo, que relega ao passado todas as coisas filmadas? $\mathrm{O}$ que dizer de nosso olhar contemplativo, de nossa escolha dessa rua específica? Onde está a verdade? E qual verdade?" (Carrière, 1995: 40).

O que marcaria a relação entre a subjetividade e a imagem tecnológica: o princípio de realidade ou a inocência da câmera? Ao nosso ver, ambas as propostas acabam por apontar para o mesmo lugar: a dicotomia entre a objetividade pura de um dispositivo técnico e a subjetividade pura daquele que manuseia este instrumento. Ambos apresentam-se em lugares estanques, "descontaminados" do outro. Da mesma forma que as imagens mentais, em princípio subjetivas, apresentam-se “contaminadas" pela visão "objetivada” destes aparelhos óticos, não são estas imagens tecnológicas manuseadas por sujeitos, que trazem em si uma história de vida 
familiar, ética, política, cultural e estética, que também acabariam por "contaminar" estas mesmas máquinas de visão?

Assim, não se trata de querer-se desviar das máquinas, já que, em última instância, estas são formas hiperdesenvolvidas e hiperconcentradas da subjetividade, mas de redimensionar tais aparelhagens, situando seu engendramento histórico. Segundo Guattari (1993), este desequilíbrio na relação homem-máquina, como componente da subjetividade capitalística ${ }^{7}$, começa a se afirmar a partir do século XVIII.

Desta forma, a questão que merece, então, ser levantada deve-se ao fato de a subjetividade, a partir do triunfo do capitalismo e, conseqüentemente, do Capital, regendo tanto as atividades humanas como a tecnologia, ter entrado numa relação de dependência com o que Guattari (1993) chamou de equipamentos maquínicos:

O universo de referência do novo cambismo generalizado não será mais uma territorialidade segmentária, mas o Capital como modo de reterritorialização semiótica das atividades humanas e das estruturas convulsionadas pelos processos maquínicos [...]. A nova "paixão capitalística" varrerá tudo o que encontrar pelo caminho; em especial as culturas e as territorialidades que, bem ou mal, haviam conseguido escapar aos rolos compressores do cristianismo (Guattari, 1993: 184-185).

Ao nosso ver, é Benjamin ([1936] 1975) que, ao discutir, ainda na primeira metade do século $\mathrm{XX}$, as técnicas de reprodução relativas à imagem, possui uma análise, eqüidistante dos apocalípticos e dos integrados, apontando pistas para além do desaparecimento da imaginação, vítima da instrumentalização da visão, ou dos estilhaços de imagens.

A possibilidade de uma obra de arte ser reproduzida inúmeras vezes traz não apenas uma mudança nas obras de arte do passado, mas impõe formas originais de arte, nas quais a reprodução técnica lhes é constitutiva e traz consigo a perda da aura. Tema recorrente em Baudelaire, que em suas poesias pensa o artista moderno como um sujeito que abdicou de sua aura, isto é, de seu status de culto, deixando-a cair no chão. $\mathrm{O}$ artista moderno, para o poeta, deve descer de seu pedestal e perder-se nas ruas, tornando-se um sujeito comum, mais um na multidão.

Você por aqui, meu caro? Você, num lugar suspeito! Você, o bebedor de quintessências? [...] Meu caro, você conhece meu pavor pelos cavalos e pelos carros. Ainda há pouco, enquanto eu atravessava a avenida, com grande pressa [...], minha auréola, num movimento brusco, escorregou de minha cabeça para a 
lama da calçada. Não tive coragem de juntá-la. Julguei menos desagradável perder minhas insígnias do que deixar que me rompessem os ossos. E depois, pensei, há males que vêm para o bem. Posso agora passear incógnito [...]. E, também, penso com alegria que algum poeta ruim há de juntá-la e vesti-la imprudentemente... (Baudelaire, citado por Benjamin, [s.d.] 1975: 61-62).

A análise da perda da aura na modernidade é retomada com muita propriedade por Benjamin (1936/1975, [s.d.] 1975): a aura representa o hic et nunc da obra de arte, isto é, seu aqui e agora, sua autenticidade e unicidade. Poderia defini-la como a aparição única de algo distante, por mais próximo que esteja. Assim, a presença única de uma obra de arte dá-lhe o estatuto de autêntica e, por isso, ela possui uma aura.

A arte e o artista, ao penetrarem na cultura de massa, perdem sua aura. $\mathrm{O}$ fenômeno da reprodutibilidade técnica tem o seu ápice na fotografia e no cinema. Em ambos, desaparece por completo o conceito de cópia e original. Anula-se a autenticidade e a unicidade do original, pois ele é igualado à cópia. Não se pode dizer, por exemplo, que o copião de um filme é mais autêntico do que as cópias que daí se reproduzem. O cinema e a fotografia trazem, em si, o caráter da reprodução. Para Benjamin ([1936] 1975, [s.d.] 1975), não se trata de uma decadência ou degenerescência da arte, mas de mudança de estatuto. A obra de arte já não pode mais ser pensada em termos auráticos. Se, antes, o valor da arte existia enquanto valor de culto, no qual a própria presença das imagens tinha mais importância do que o fato de serem vistas, havendo uma restrição espaço-temporal de exibição, a exemplo dos templos e das igrejas, com a emancipação da arte de seu uso ritual elas passam a ser mais exibíveis - um quadro é mais passível de exibição do que um mosaico, e a fotografia de ambos mais ainda. Assim, a arte passa a ter valor enquanto realidade exibível.

As técnicas de reprodução e suas inúmeras possibilidades de exibição trazem consigo uma certa democratização do acesso à arte, provocando o surgimento da cultura de massa pautada, dentre outras coisas, na tecnologia da imagem. A dessacralização da arte também muda completamente a interação com o espectador. Se, antes, protegida por sua aura, a obra de arte mantinha-se distante, com as técnicas de reprodução acaba por se manter cada vez mais próxima do espectador, acarretando uma mudança significativa na percepção do sujeito moderno. A percepção torna-se saturada pelo domínio da imagem. Desde o final do século XIX, o choc da multidão, advindo da nova ocupação urbana das grandes cidades, a pintura impressionista, que anula os contornos definidos, bem como a fotografia estabelecem um olhar moderno para o discernimento desta faculdade recém ad- 
quirida ${ }^{8}$. Também referindo-se a Baudelaire, que se propôs a aparar os chocs originários das multidões das grandes cidades e transformá-los em poesia, Benjamin ([1936] 1975, [s.d.] 1975) teoriza sobre esta nova percepção marcada pelo impacto e pela colisão. A análise benjaminiana com relação ao choc não é apenas hostil, mas, como no próprio Baudelaire, compreende também o fascínio.

$\mathrm{O}$ avanço do capitalismo e da tecnologia produz o crescimento urbano e sua correria habitual. As Passagens, galerias parisienses por onde se esbarram os transeuntes, estão repletas de estímulos advindos não só da multidão, mas de lojas que estampam em suas vitrines a última moda, novos produtos a serem consumidos, preconcebendo o shopping center atual ${ }^{9}$. Neste novo espaço urbano, o homem de negócios, a dona de casa, transeuntes em sua movimentação maníaca se encontram com o flâneur, que perambula pela cidade no seu ritmo próprio.

Os estímulos tornam-se cada vez mais bruscos, cada vez mais desconcertantes e, na ruptura desta proteção, apresentam-se os chocs. Para se proteger deles, o homem moderno utiliza-se mais da consciência e menos da memória, isto é, mais da vivência relacionada ao presente e menos da experiência ligada à conservação, à duração da memória.

Experiência e vivência se opõem não só como duas formas de percepção, mas como duas formas de o indivíduo se relacionar com a máquina, a técnica, marcadas pelo gesto brusco inaugurado pela invenção do fósforo, passando pelo automatismo de novas máquinas e suas centenas de botôes e chegando ao "click" fotográfico: "Bastava apertar um dedo para fixar um acontecimento por um período ilimitado de tempo. A máquina comunicava ao instante, por assim dizer, um choc póstumo" (Benjamin, [s.d.] 1975: 49).

No entanto, comparada ao cinema, a fotografia representou uma "brincadeira de criança" na vivência do $c h o c$. No campo perceptivo, o cinema significou uma revolução. $\mathrm{O}$ espectador é ambivalentemente distraído e atento, configurando uma nova forma de percepção. O olho não consegue se fixar, pois, mal capta uma imagem, outra já aparece. Enquanto a pintura exige concentração, fazendo o espectador "mergulhar" na tela, no cinema, com sua proposta de diversão, é a obra de arte que penetra nas massas. A câmera possibilitou que o sujeito visse imagens que, até então, eram imperceptíveis ao olho humano, provocando o surgimento de uma nova realidade.

Fica bem claro, em conseqüência, que a natureza que fala à câmera é completamente diversa da que fala aos olhos, mormente porque ela substitui o espaço onde o homem age conscientemente por outro onde sua ação é inconsciente. Se é banal analisar, pelo menos globalmente, a maneira de andar dos homens, 
nada se sabe com certeza de seu estar durante a fração de segundo em que estica o passo. [...] É nesse terreno que penetra a câmera, com todos os seus recursos auxiliares de imergir e de emergir, seus cortes e seus isolamentos, suas extensões de campo e suas acelerações, seus engrandecimentos e suas reduções. Ela nos abre, pela primeira vez, a experiência de um inconsciente visual, assim como a psicanálise nos abre a experiência do inconsciente instintivo (Benjamin, [1936] 1975: 29).

\section{Cultura DA IMAGEM: UMA NOVA AURA?}

Benjamin ([1936] 1975, [s.d.] 1975) preconizou o fim da arte aurática, em seu aspecto de culto e de autenticidade. Não obstante, boa parte das imagens atualmente veiculadas pela mídia parece oferecer um novo culto, uma aura de segunda ordem, não mais baseada na autenticidade, na originalidade, mas no excesso de exposição, no impacto, no choc, no mesmo movimento em que estes "objetos de culto", efêmeros, rapidamente substituíveis, permanecem inacessíveis. Circunscrita a épocas distintas, a arte aurática caracterizava-se pelo excesso de transcendência e atualmente se afirmaria exatamente pela sua ausência. A fetichização da arte e a mercantilização de bens culturais tornaram-se o novo culto da cultura da imagem. Artistas são fabricados e, posteriormente, "endeusados", engendrando, em última instância, uma espécie de "produção instrumental da aura".

Esta nova aura cercaria não só a obra de arte em si, mas artistas de um modo geral e pessoas superexpostas na mídia. Morin ([1962] 1990) analisa os olimpianos modernos - astros de cinema, de TV, cantores, esportistas, e poderíamos acrescentar top models, apresentadores, participantes de reality shows, enfim, todas as celebridades, ou seja, pessoas superexpostas na mídia - como um dos sustentáculos básicos da cultura de massa. Semideuses, metade deuses nos papéis que eles encarnam, metade humanos na existência privada que eles levam, têm suas vidas acompanhadas de perto através dos meios de comunicação de massa. Em 1962, o autor escrevera:

A informação transforma esses olimpos em vedetes da atualidade. Ela eleva à dignidade de acontecimentos históricos acontecimentos destituídos de qualquer significação política, como as ligaçóes de Sorya e Margaret, os casamentos e divórcios de Marilyn Moroe ou Liz Taylor, os partos de Gina Lollobrigida, Brigitte Bardot, Farah Diba ou Elizabeth da Inglaterra (Morin, [1962] 1990: 105). 
A possibilidade de se consumir um artista vendo um filme, uma novela, ou através de produtos aos quais seu nome está associado, ou de sua própria imagem estampada em camisetas e revistas, cria uma ilusão de proximidade, ao mesmo tempo que alimenta sua mitificação. Aliás, como assinala Baudrillard ([1974] 1995), quando alguém compra um determinado cigarro ou sabonete cuja propaganda está associada a uma dessas personalidades olimpianas não está consumindo um produto, mas um conceito: um status ou sex appeal. Baudrillard recorre ao campo da linguagem e explica a lógica do consumo segundo a manipulação de significantes sociais, isto é, não se consome o objeto em si, mas o que ele representa (conforto, status...), onde um signo se liga a outro, constituindo o valor-signo. Desta forma, qualquer objeto pode ser substituído por outro, contanto que exerça a mesma função. Assim, o celular ou o carro importado, para além de um utensílio, funcionam como elemento de prestígio e diferença social. $\mathrm{O}$ objeto, ao assumir o lugar de signo, deixa de estar ligado ao binômio necessidade/satisfação, relacionado à finalidade racional do objeto, para entrar na ordem do desejo, fundado na carência, campo móvel e inconsciente de significação, que se ressignifica localmente nestes mesmos objetos: "se se admitir antes que a necessidade nunca é tanto a necessidade de tal objeto quanto a 'necessidade' de diferença (o desejo do sentido social) compreender-se-á, então, por que é que nunca existe satisfação completa, nem definição de necessidade" (Baudrillard, [1974] 1995: 78).

Posteriormente, Morin (1986) aponta a crise dos olimpianos provocada a partir da década de 60 , em que a mitologia da felicidade torna-se a problemática da felicidade, e a infelicidade destes artistas que vivem, muitas vezes, no alcoolismo, nas drogas, levando até mesmo ao suicídio, comprometeria o bem-estar encarnado nestes ídolos, suportes da cultura de massa. No entanto, ao nosso ver, a base continuaria a mesma, isto é, cada vez mais próximos, o que os torna aparentemente mais humanos, os olimpianos, suas alegrias e suas tristezas comovem o grande público e servem de alimento ao culto. O sofrimento, a desgraça de alguns dos ídolos são acompanhados pela imprensa e pela mídia televisiva e transformados em espetáculo, atendendo, em última instância, à manutenção da aura instrumentalizada. A aura deixada no chão pelo poeta foi recuperada de forma perversa pela cultura da imagem, mas não irremediavelmente...

\section{CRIAÇÃo, RELEVo E EXPERIÊNCIA}

Vimos que as imagens retratadas na fotografia, a imagem-movimento do cinema e, atualmente, do vídeo e das redes de informática acabam por imprimir novos contornos à subjetividade. $\mathrm{O}$ eu, o outro, o mundo, tudo pode ser registra- 
do pela câmera, tornando qualquer universo, mesmo que distante, próximo e presente. Estes fatos, porém, não carregam a priori a impossibilidade de criação, pois o potencial criativo da fotografia, do cinema ou do vídeo é inesgotável. Todos estes suportes têm muito a dizer sobre a existência contemporânea. O problema não está na relação entre subjetividade e imagem tecnológica, mas na homogeneização das imagens em padrões, gostos, impondo um referencial estético único no cotidiano.

Como se daria a criação onde as tecnologias da imagem se baseiam no choc, no imediatismo, na vivência? Como não só a fotografia e o cinema, mas também o vídeo, poderiam imprimir a esse choc a criação? Estas novas artes, baseadas na reprodução técnica, têm como desafio encontrar sua expressão criadora na arte do instante.

Não se trata, portanto, de uma relação de causalidade entre a falência da visão através do domínio da máquina e sua insaciável possibilidade de repetição, mas dos usos delegados a estas máquinas. Decorridos vários anos após a invenção do cinema, e com a subjetividade contemporânea cada vez mais atravessada pela imagem tecnológica, podemos inferir que, apesar de a vivência ainda preponderar, intrínseca ao imediatismo do consumo, há algo de duração, da experiência benjaminiana, na relação do sujeito com a profusão de imagens.

A duração à qual nos referimos na relação entre subjetividade e imagem encontra-se menos na memória representativa de uma cena de um filme marcante, ou de uma foto chocante, e mais na impossibilidade de esgotamento de sentido total de uma imagem, marcada por sua incompletude, fazendo-a ecoar e ressoar em nós. Exatamente porque somos moldados na e pela imagem é que ela nos é tão familiar, e é na infinidade de significações que ela nos traz que conseguimos compreendê-la: a imagem passa, necessariamente, por alguém que a produz ou reconhece. Assim sendo, ao admitirmos a dimensão polifônica da "cultura da imagem" 10 , colocamos em evidência a questão da alteridade, ou seja, o sentido da imagem se constitui não apenas entre o sujeito e os aparelhos que servem como suportes das imagens, as máquinas de visão, mas se constrói na relação com as imagens produzidas pelos aparelhos e mediadas pelo diálogo com os outros sujeitos que, igualmente, experimentam a avalanche de estímulos que nos circundam cotidianamente. É no confronto consciente destes diferentes modos de experiência no mundo das imagens que se torna possível encaminhar soluções que conduzam à singularização da subjetividade como combate à sujeição, ou à submissão.

Criar relevos na enxurrada de imagens, ou quem sabe deixar-se estranhar através delas, para daí poder criar novas narrativas. Ao invés da aniquilação absoluta, assim como Benjamin viu em Baudelaire a incumbência de aparar os chocs 
sem sucumbir a eles, caberia a nós a mesma tarefa, transformando o imediatismo da vivência, que não quer deixar rastros, em duração, em experiências.

\section{REFERÊNCIAS BIBLIOGRÁFICAS}

Adorno, T. \& Horkheimer, M. (1944). Dialética do esclarecimento. Rio de Janeiro: Jorge Zahar, 1986.

Aumont, J. (1995). A imagem. Campinas: Papirus.

Baudrillard, J. (1974). A sociedade de consumo. Rio de Janeiro: Elfos, 1995.

Benjamin, W. (1936). A obra de arte na época de suas técnicas de reprodução. Coleção Os Pensadores, v. XLVIII (pp. 9-34). São Paulo: Abril, 1975.

- (s.d.). Sobre alguns temas em Baudelaire. Coleção Os Pensadores, v. XLVIII (pp. 35-62). São Paulo: Abril, 1975.

Bernardet, J. C. (1980). O que é o cinema? São Paulo: Brasiliense.

Calvino, I. (1990). Seis propostas para o próximo milênio. São Paulo: Companhia das Letras.

Carrière, J. C. (1995). A linguagem secreta do cinema. Rio de Janeiro: Nova Fronteira.

Debray, R. (1992). Vie et mort de l'Image: une histoire du regard en Occident. Paris: Gallimard, collection Folio/Essais.

Guattari, F. (1990). As três ecologias. Campinas: Papirus.

- (1992). Caosmose: um novo paradigma estético. Rio de Janeiro: Editora 34.

. (1993). Da produção de subjetividade. Em Parente, A. (Org.). Imagem-máquina: a era das tecnologias do virtual (pp. 177-194). Rio de Janeiro: Editora 34.

Guattari, F. \& Rolnik, S. (1986). Micropolítica: cartografias do desejo. Petrópolis: Vozes.

Lins, D. (1997). Cultura e subjetividade. São Paulo: Papirus.

Machado, A. (1994). As imagens técnicas: da fotografia à sintese numérica. Imagens - Tecnologia, 3, 8-14.

Miranda, L. (2000). Subjetividade: a (des)construção de um conceito. Em Jobim e Souza, S. (Org.). Subjetividade em questão: a infância como crítica da cultura (pp. 29-46). Rio de Janeiro: 7 letras.

Morin, E. (1962). Cultura de massas no século XX - Neurose. São Paulo: Forense Universitária, 1990.

. (1986). Cultura de massas no século XX - Necrose. São Paulo: Forense Universitária.

Virilio, P. (1992). Attention les yeux! Em Daney, S. (Org.). Trafic (pp. 83-88). Paris: Éditions P.O.L..

(1994). A máquina de visão. Rio de Janeiro: José Olímpio. 


\section{NOTAS}

1 O presente artigo faz parte da pesquisa realizada para o Doutorado em Psicologia pela PUCRio. A tese de doutorado intitula-se: Criadores de Imagens, Produtores de Subjetividade: a experiência da TV Pinel e da TV Maxambomba, Rio de Janeiro, PUC-Rio, 2002. Durante o doutorado a autora foi bolsista do CNPq e da CAPES para a realização do Doutorado Sanduíche no Département des Sciences de l'Education em Paris VIII.

2 O conceito de subjetividade é tomado segundo a problematização de Guattari (1992) que, ao ultrapassar a oposição clássica entre sujeito individual e sociedade, imprime à subjetividade um registro eminentemente social. A subjetividade seria atravessada transversalmente por instâncias individuais, coletivas e institucionais: "A subjetividade não é passível de totalização ou de centralização no indivíduo. Uma coisa é a individuação do corpo. Outra é a multiplicidade dos agenciamentos de subjetivação: a subjetividade é essencialmente fabricada e modelada no registro do social" (Guattari \& Rolnick, 1986: 31). Para melhor compreensão do conceito de subjetividade aqui proposto, ver também Guattari (1990, 1992, 1993), Lins (1997) e Miranda (2000).

3 Em 1936, Walter Benjamin escreveu A Obra de arte na época de suas técnicas de reprodução (1975). O subtítulo aqui escolhido, de forma proposital, faz alusão a este ensaio, forte referência de nossa análise.

4 Fotografia e artes mantinham uma relação ambivalente. Se, por um lado, a invenção do daguerreótipo foi apresentada na Academia Francesa de Ciências, e não na de Belas Artes, tal fato não impediu, por outro, o tom desgostoso de Delaroche, pintor de batalhas, ao afirmar: "A partir de hoje a pintura está morta" (citado por Debray, 1992: 366; tradução nossa). Assumindo outra postura, Picasso posteriormente afirmaria: "A fotografia veio a ponto de liberar a pintura de toda literatura da anedota e mesmo do sujeito" (citado por Debray, 1992: 369; tradução nossa). Ao mesmo tempo, porém, a fotografia tentava se afirmar como arte, e é também conhecido o fato de fotógrafos numerarem as cópias e queimarem seus negativos em happenings, a fim de darem às suas fotos um estatuto de obra de arte.

5 Na primeira metade do século XX, Theodor Adorno, Max Horkheimer e Walter Benjamin, representantes da Escola de Frankfurt, formularam uma Teoria Crítica da cultura em que analisaram as relaçôes entre alguns fenômenos culturais e a emergência de diversas técnicas de reprodução, como a fotografia e o cinema, no estágio do capitalismo de sua época. Tematizado dentro de um enfoque materialista-dialético, o conceito adorniano de Indústria Cultural trabalhou as mudanças no campo das artes e da cultura, denunciando seu empobrecimento, uma vez que estas passam a ser submetidas à ratio do mercado (Adorno \& Horkmeimer, [1944] 1986). Já Benjamin ([1936] 1975, [s.d.] 1975) analisou as mudanças, procurando manter a contradição ambivalente dos seus aspectos positivos e negativos, 
centrando sua análise no exame das conseqüências na esfera do sujeito, nas alterações espaçotemporais e perceptuais com relação a esta nova produção cultural.

6 Segundo Machado (1994), alguns cineastas saem desta linha naturalista, como é o caso, dentre outros, de Luís Buñuel, mas é a vídeo-arte que propõe um verdadeiro rompimento paradigmático com a pretensão de realidade.

7 Guattari acrescentou o sufixo "ístico" a "capitalista" por lhe parecer necessário criar um termo que possa designar não apenas as sociedades qualificadas como capitalistas, mas também setores do "Terceiro Mundo" ou do capitalismo "periférico", assim como as economias ditas socialistas dos países do leste, que viveram numa espécie de dependência e contradependência do capitalismo. Tais sociedades, segundo Guattari, em nada se diferenciaram do ponto de vista de produção de subjetividade. Elas funcionaram segundo uma mesma cartografia do desejo no campo social, uma mesma economia libidinal-política (Rolnik, citado por Guatarri \& Rolnik, 1986: 15).

8 Mantivemos o termo $c h o c$ do original em francês conforme consta na versão da Coleção Os Pensadores. Ver Benjamin ([s.d.] 1975).

9 A propósito desta experiência urbana da virada do século XIX, Baudelaire refere-se prioritariamente à Paris que, por representar a síntese do novo panorama urbano, é considerada pelo poeta a capital daquele século.

${ }^{10}$ Polifonia de imagens diz respeito à simultaneidade de imagens que evocam relações de sentido no sujeito. $\mathrm{Na}$ interação com as imagens, cabe ao sujeito interpretá-las como signos e desenvolver modos de leitura, exercendo a leitura das imagens como atividade crítica.

Recebido em 17 de junho de 2007 Aceito para publicação em 2 de agosto de 2007 